\title{
Paving the PICC journey: building structures, process and engagement to improve outcomes
}

Mohamad Fakih, $^{1,2}$ Lisa Sturm ${ }^{1}$

${ }^{1}$ Quality Department, Clinical \& Network Services, Ascension, St Louis, Missouri, USA

${ }^{2}$ Wayne State University School of Medicine, Detroit, Michigan, USA

\section{Correspondence to}

Dr Mohamad Fakih, Quality Department, Clinical \& Network Services, Ascension, St Louis, MO, USA;

Mohamad.Fakih@ascension.org

Accepted 8 February 2021

\section{Linked}

- http://dx.doi.org/10.1136/ bmjqs-2020-011987

\section{Check for updates}

(C) Author(s) (or their employer(s)) 2021. No commercial re-use. See rights and permissions. Published by BMJ.

To cite: Fakih M, Sturm L. BMJ Qual Saf Epub ahead of print: [please include Day Month Year]. doi:10.1136/ bmjqs-2020-012910
Many patients admitted to hospital require venous access to infuse medications and fluids. The most commonly used device, the peripheral venous catheter, ranges from 2.5 to $4.5 \mathrm{~cm}$ in length, and is typically used for less than 5 days. The midline, a relatively newer peripheral venous catheter, is up to $20 \mathrm{~cm}$ in length, but does not reach the central veins, and may be used for up to 2 weeks. A peripherally inserted central venous catheter (PICC) is a longer catheter that is placed in one of the arm veins and extends to reach the central veins. The PICC is used for longer periods of time compared with peripheral intravenous devices, and initially gained popularity as a convenient vascular access device used in the outpatient and home settings. Its premise has been to provide access that lasts for weeks, that is fairly safe and easily manageable. Patients often require central venous access when hospitalised, with more than half of patients in intensive care, and up to $20 \%$ in those cared for in the non-intensive care wards. ${ }^{1}$ Common indications for PICC use in the acute care setting include the requirement for multiple and frequent infusions (eg, antibiotics, parenteral nutrition), the administration of medications incompatible with peripheral infusion, invasive haemodynamic monitoring in critically ill patients, very poor venous access and frequent need for blood draws. ${ }^{2}$ Specially trained healthcare workers place PICCs, often nurses from a vascular access team (VAT), or interventional radiologists. The VAT is comprised of skilled nurses, with either medical/surgical, emergency department or intensive care unit backgrounds. Contrary to other healthcare workers that place PICCs, the VAT's primary function is to place PICCs, and optimise the infusion delivery, through a safe and effective process. Its scope includes assessment for need, peripheral and central device insertion, monitoring of use and removal. ${ }^{3}$

In their study of five hospitals within the Veterans Administration (VA) healthcare systems in the USA, Krein et $a l^{4}$ underscore the importance of a formal VAT to formulate and implement explicit appropriateness criteria, ensure timely insertion and safe management and direct patient education around PICC use. They found that team structures supporting line placement vary across hospitals from a dedicated team, to individual nurses trained in placement, to hospitals where only interventional radiologists insert PICCs. The presence of a VAT was associated with more defined criteria for PICC use, but a recurrent theme was inadequate interdisciplinary dialogue. Although qualitative data were gathered at five VA hospitals only, the study's findings reflect the variation in PICC placement and use, whether in academic or community, small or large hospitals.

An important factor in variation in the approach to PICC line placement and management is the availability of resources and expertise at the hospital site. For example, if healthcare workers have suboptimal skills to place peripheral venous catheters, including midlines, ${ }^{5}$ clinicians may resort to ordering more PICCs unnecessarily to fill that void. Furthermore, as revealed in Krein's study, a hospital that does not have the expertise to learn about alternative devices, such as those with lower risks and shorter dwell times (eg, midlines), may resort to using more PICCs than necessary. Similarly, hospitals without clinicians skilled or comfortable placing other central lines ${ }^{6}$ may rely more on using PICCs. In addition, the lack of an available VAT to place PICCs using ultrasound guidance may 
result in more referrals to interventional radiology for placement, potentially exposing the patient to avoidable radiation during fluoroscopy. ${ }^{7}$

We propose an approach to improve the appropriate and safe use of PICCs by focusing on three elements that address the findings by Krein and colleagues: establishing a structure powered by a VAT; anchoring a standardised process for line selection, insertion and care; and promoting adoption by engagement with the key stakeholders.

Establishing a structure to support placement and management of PICCs depends on whether the number of devices placed is enough to support the creation of a dedicated vascular access programme. Leadership plays a critical role to invest the resources for a functional VAT, understanding the financial and quality benefits associated. ${ }^{8}$ Not realising its value, hospital leaders may view the VAT as a non-revenue-generating service, putting it at risk when considering cost reduction strategies. The value of the VAT expands from mitigating preventable events (eg, deep venous thrombosis, infection) to enhancing patient experience (eg, less attempts to place a peripheral device). ${ }^{9}$ In addition, better outcomes help curb the financial risks (eg, hospital-acquired condition penalties) ${ }^{8}$ and improve hospital ratings. The VAT's role encompasses placing PICCs and guaranteeing the proper selection of the intravascular device and its appropriate use. ${ }^{2}$
The second element involves standardising processes for line selection and care, regardless of who is taking care of the device. Implementing policies to address indications, placement and maintenance and using standardised kits help minimise variation. The creation of policies should be achieved through a multidisciplinary approach with VAT, nurses and physicians. The VAT can act as the 'gate keeper' evaluating whether the reason for PICC placement is aligned with indications. In addition, the VAT plays a critical role supporting nurses' competencies for venous catheter use (eg, aseptic access and maintenance, addressing complications and mitigating risk $)^{10}$ to reduce mechanical ${ }^{11}$ and infectious complications. ${ }^{12}$ The VAT performs regular rounds to mitigate process gaps (eg, dressing site intactness) and to identify complications (eg, PICC site erythema or drainage, arm swelling), and provides timely feedback on clinical performance. The VAT can also serve as subject matter experts to the ordering physicians for the appropriate device type, based on vessel size and indications for use, how many lumens, site selection and a de-escalation plan for the patient prior to discharge. It also provides services should a devicerelated complication occur (eg, clotting), and works with clinicians to remedy the issue and salvage the device, thereby preventing a patient from losing their vascular access and/or having to replace it.

\begin{tabular}{|c|c|}
\hline Discipline & Mitigate PICC harm \\
\hline Vascular access team & $\begin{array}{l}\text { Advise and recommend optimal device choice per patient; preferential single-lumen PICC to reduce complication risk; ensure } \\
\text { proper insertion and maintenance; evaluate quality processes related to line care (eg, dressing intactness, occlusion rates, } \\
\text { phlebitis, infections, thrombosis; line de-escalation). }\end{array}$ \\
\hline Nursing & Play a key role in the choice of peripheral access device and line care. \\
\hline Bedside nurses & $\begin{array}{l}\text { Establish competencies for placing peripheral venous catheters; adhere to the standard of intravenous line care to reduce } \\
\text { occlusion risk (eg, avoid drawing blood from lines) and prevent infectious complications; evaluate the continued PICC need and } \\
\text { risk; train when to escalate to the vascular access team for expertise. }\end{array}$ \\
\hline Infection preventionists & Provide feedback on central line use and infectious complications; participate in development of policies and new product reviews \\
\hline Pharmacists & $\begin{array}{l}\text { Evaluate switch to oral medications; address the use of alteplase as a marker for occlusion; advise on vesicant and irritant } \\
\text { infusions. }\end{array}$ \\
\hline Physicians & Play a key role in requesting PICC line placement and also its duration of use. \\
\hline Infectious diseases & $\begin{array}{l}\text { Assess the need for long-term parenteral antimicrobials versus potential oral alternatives; promote optimal device choice and } \\
\text { discontinuation of PICC when no longer needed. }\end{array}$ \\
\hline Surgery & Assess the need for parenteral versus enteral nutrition; evaluate the optimal short-term central line to use. \\
\hline Hospitalists/internists & $\begin{array}{l}\text { Care for a large number of patients; avoid ordering PICCs out of convenience (eg, for blood draws); understand the appropriate } \\
\text { indications for use; daily evaluate device for complication risk and necessity. }\end{array}$ \\
\hline Intensivists & $\begin{array}{l}\text { Choose the optimal line and place central venous catheters; daily evaluate device for complication risk and necessity; further } \\
\text { evaluate the need for central access when ready to transfer out of intensive care. }\end{array}$ \\
\hline Physicians in training & $\begin{array}{l}\text { Evaluate on the indications for vascular device use, place central venous catheters and address discontinuation; address their } \\
\text { competencies for placing and maintaining catheters; closely partner with bedside nurses on device necessity and risk. }\end{array}$ \\
\hline Nephrologists & Champion the importance of avoiding PICC placement in patients with chronic kidney disease to reserve venous access. \\
\hline Interventional radiologists & $\begin{array}{l}\text { Partner with the vascular access team on patient selection for PICC (preferably the vascular team performs the procedures } \\
\text { preventing patient exposure to fluoroscopy); obtain reason for PICC placement; use single-lumen PICC unless otherwise } \\
\text { requested. }\end{array}$ \\
\hline Administrative leaders & $\begin{array}{l}\text { Provide support for an effective vascular access team; understand the adverse quality outcomes (eg, patient experience, deep } \\
\text { venous thrombosis, infection) and financial risks (eg, hospital-acquired condition penalties) without an effective vascular access } \\
\text { team. }\end{array}$ \\
\hline
\end{tabular}


The last element, and perhaps most significant, is to enhance the adoption of best practices through a partnership with the key stakeholders. PICC-associated outcomes are not only owned by the VAT, rather it is the responsibility of the clinicians, physicians and nurses to achieve those goals (table 1). Physicians are an essential stakeholder group to engage as they are the ones responsible for ordering the PICC. An identified physician champion who partners and empowers the VAT will help resolve any barriers and be a liaison with the local physician community. ${ }^{13}$ The ideal physician champion should have the respect of peers, understand process optimisation and promote quality improvement. They need to be well versed on the appropriate indications for PICC use, the associated complications and risks and alternatives to the device. The physician champion engages the leaders of the key disciplines responsible for requesting a PICC, educating them on the appropriate indications for use, the outcomes associated with PICC use, inviting them to be partners and responding to any of their concerns.

What about the key physician disciplines to engage? Physicians can play an active role in enhancing PICC use through avoiding the unnecessary use of infusions. The consultation of infectious diseases specialists for intravenous antibiotic use appropriateness has been associated with less PICC use and lower complications. ${ }^{14}$ Similarly, having a surgeon support the decision for whether enteral or parenteral nutrition is needed will help reduce unnecessary device use. ${ }^{15}$ Disciplines like hospitalists or general internists care for a large number of patients and often order PICCs for venous access, ${ }^{16}$ while nephrologists may advocate avoiding the use of PICCs in the chronic kidney disease population in an effort for vein preservation. ${ }^{17}$ In hospitals with teaching programmes, the VAT and its physician champion may educate physicians in training on device choice, placement and duration of use, and address with their faculty competencies for line management. ${ }^{18}$ Engaging these disciplines, elucidating the indications for appropriate use and providing feedback and local data on the potential harm ensure accountability and further attention to PICC safety.

In summary, the PICC is one of the primary solutions to achieve vascular access. With up to one in five patients at risk for developing complications, ${ }^{19}$ it is incumbent on us to ensure that these devices are properly used and maintained. Identifying and overcoming system barriers are key to delivering sustainable safe outcomes. As a first step, clinical and administrative leaders, realising the financial and quality benefits, need to support the structure reflected by the VAT to enhance PICC care. Second, the VAT must partner with disciplines (particularly nursing) to promote and ensure adequate competencies for placement and maintenance. Finally, clinical disciplines caring for the patient should instil a collaborative environment for better decision-making on when central access is required, and what device provides the safest and most effective delivery of care.

Funding The authors have not declared a specific grant for this research from any funding agency in the public, commercial or not-for-profit sectors.

Competing interests None declared.

Patient consent for publication Not required.

Provenance and peer review Commissioned; internally peer reviewed.

\section{REFERENCES}

1 Dudeck MA, Weiner LM, Allen-Bridson K, et al. National healthcare safety network (NHSN) report, data summary for 2012, device-associated module. Am J Infect Control 2013;41:1148-66.

2 Chopra V, Flanders SA, Saint S, et al. The Michigan appropriateness guide for intravenous catheters (magic): results from a Multispecialty panel using the RAND/UCLA appropriateness method. Ann Intern Med 2015;163:S1-40.

3 Gorski LA, Hadaway L, Hagle ME, et al. Infusion therapy standards of practice, 8 th edition. J Infus Nurs 2021;44:S1-224.

4 Krein SL, Harrod M, Weston LE, et al. Comparing peripherally inserted central catheter-related practices across hospitals with different insertion models: a multisite qualitative study. BMJ Qual Saf 2020. doi:10.1136/bmjqs-2020-011987. [Epub ahead of print: 24 Dec 2020].

5 Cawcutt KA, Hankins RJ, Micheels TA, et al. Optimizing vascular-access device decision-making in the era of midline catheters. Infect Control Hosp Epidemiol 2019;40:674-80.

6 Huang GC, Smith CC, Gordon CE, et al. Beyond the comfort zone: residents assess their comfort performing inpatient medical procedures. Am J Med 2006;119:71.e17-71.e24.

7 Jonczyk M, Gebauer B, Schnapauff D, et al. Peripherally inserted central catheters: dependency of radiation exposure from puncture site and level of training. Acta Radiol 2018;59:688-93.

8 Centers for Medicare \& Medicaid Services. Hospital-Acquired conditions. Available: http://www.cms.gov/Medicare/MedicareFee-for-Service-Payment/HospitalAcqCond/Hospital-Acquired_ Conditions.html [Accessed 23 Dec 2020].

9 Corcuera Martínez $\mathrm{M}^{\mathrm{a}}$ Inés, Aldonza Torres M, Díez Revilla Ana $\mathrm{M}^{\mathrm{a}}$, et al. Impact assessment following implementation of a vascular access team. J Vasc Access 2020:112972982098428.

10 Fakih MG, Heavens M, Ratcliffe CJ, et al. First step to reducing infection risk as a system: evaluation of infection prevention processes for 71 hospitals. Am J Infect Control 2013;41:950-4.

11 Pan M, Meng A, Yin R, et al. Nursing interventions to reduce peripherally inserted central catheter occlusion for cancer patients: a systematic review of literature. Cancer Nurs 2019;42:E49-58.

12 Krein SL, Kuhn L, Ratz D, et al. Use of designated nurse PICC teams and CLABSI prevention practices among U.S. hospitals: a survey-based study. J Patient Saf 2019;15:293-5.

13 Fakih MG, Krein SL, Edson B, et al. Engaging health care workers to prevent catheter-associated urinary tract infection and avert patient harm. Am J Infect Control 2014;42:S223-9.

14 Vaughn VM, O'Malley M, Flanders SA, et al. Association of infectious disease physician approval of peripherally inserted 


\section{Editorial}

central catheter with appropriateness and complications. JAMA Netw Open 2020;3:e2017659.

15 Pernar LIM, Wolf LL, Seshadri A, et al. Impact of a SurgeonLed peripherally inserted central venous catheter team on peripherally inserted central venous catheter-related complications and costs. Surg Infect 2016;17:352-6.

16 Chopra V, Kuhn L, Flanders SA, et al. Hospitalist experiences, practice, opinions, and knowledge regarding peripherally inserted central catheters: results of a national survey. J Hosp Med 2013;8:635-8.
17 McGill RL, Tsukahara T, Bhardwaj R, et al. Inpatient venous access practices: PICC culture and the kidney patient. J Vasc Access 2015;16:206-10.

18 Agency for Healthcare Research and Quality. Resident physicians as champions in preventing device-associated infections. Available: https://www.ahrq.gov/hai/cauti-tools/ phys-championsgd/index.html [Accessed 1 Jan 2021].

19 Chopra V, Smith S, Swaminathan L, et al. Variations in peripherally inserted central catheter use and outcomes in Michigan hospitals. JAMA Intern Med 2016;176:548-51. 